\title{
Non-traumatic spinal cord injury in Norway 2012-2016: analysis from a national registry and comparison with traumatic spinal cord injury
}

\author{
A. Halvorsen ${ }^{1,2} \cdot$ A. L. Pettersen ${ }^{1} \cdot$ S. M. Nilsen ${ }^{1,3} \cdot$ K. Krizak Halle $^{1} \cdot$ E. Elmenhorst Schaanning ${ }^{4} \cdot$ T. Rekand $^{5,6}$
}

Received: 10 August 2018 / Revised: 8 November 2018 / Accepted: 8 November 2018 / Published online: 14 December 2018

(c) International Spinal Cord Society 2018

\begin{abstract}
Study design Registry-based cross-sectional study.

Objectives To describe and analyze epidemiological and demographic characteristics of non-traumatic spinal cord injury (NTSCI) and to compare persons with NTSCI and traumatic spinal cord injury (TSCI).

Setting A total of 225 non-traumatic and 349 traumatic SCI patients were admitted for primary rehabilitation at one of the three specialized SCI departments in Norway (located in Bergen, Trondheim, and Oslo) from 2012 to 2016. Patients who consented to registration in the Norwegian Spinal Cord Injury Registry (NorSCIR) were included.

Methods Data were collected using the International SCI Core Data Set, as recommended by the International Spinal Cord Society (ISCoS). Demographics and injury characteristics were analyzed descriptively. The NTSCI and TSCI groups were compared using a Mann-Whitney $U$ test and chi-square test.

Results The mean age of the NTSCI patients was 55 years, and 59\% were male. The incidence of NTSCI was 7.7-10.4 per million person-years, which is lower than the incidence of TSCI. NTSCI individuals were older, less severely injured, and their length of stay at the hospital was shorter than the TSCI individuals. The results may be influenced by the inclusion criterion in the registry. This makes the analyzed sample for NTSCI less complete. However, the majority of patients with nonprogressive NTSCI are included in the NorSCIR.

Conclusion For the first time, we are able to provide the national epidemiological status on NTSCI based on available data from the national registry. Further studies are required to improve the capture of NTSCI for future incidence studies.
\end{abstract}

\section{Introduction}

The Norwegian Spinal Cord Injury Registry (NorSCIR), authorized by the Ministry of Health and Care Services as a National Quality Registry, provides national data on both NTSCI and TSCI. Compared with TSCI, there are relatively few publications about NTSCI. One reason for this may be that many spinal cord injury registries only include persons with TSCI.

NorSCIR was established by the three specialized SCI departments in Norway in cooperation with the National Spinal Cord Injuries Association. These three hospitals in Norway provide specialized rehabilitation to

A. Halvorsen

annette.halvorsen@stolav.no

Extended author information available on the last page of the article individuals with non-traumatic or traumatic spinal cord injuries.

NorSCIR is based on the International SCI Data Sets developed by ISCoS [1]. One of the aims of the NTSCI subsection of the ISCoS Prevention Committee is to disseminate NTSCI data through global maps for spinal cord injury epidemiology [2].

To our knowledge, epidemiological studies of NTSCI in Norway have never been published. Through this registry-based cross-sectional study, we aim to estimate the incidences based on available data and describe the epidemiological characteristics of non-traumatic spinal cord injury. In addition, we compare demographics and outcomes of patients with non-traumatic and traumatic spinal cord injuries who have received rehabilitation at the same specialized rehabilitation centers. 


\section{Methods}

\section{Setting and population}

The Norwegian population was 4.99 million on January 1, 2012 and 5.26 million on December 31, 2016 [3]. All patients who were admitted to one of the three specialized SCI departments for primary rehabilitation of a nontraumatic or traumatic spinal cord injury or cauda equina injury and who consented to registration in NorSCIR from 2012 to 2016 were included. An epidemiologic analysis regarding traumatic SCI was performed separately, and it provides the basis for the comparisons made between NTSCI and TSCI in this study [4].

Annual analyses reveals $>90 \%$ coverage during the entire study period [5]. To calculate the coverage ratio, the number of patients in the registry is compared with the patient data from electronic medical records.

\section{Study design}

A registry-based cross-sectional study of incidence, clinical findings, and outcomes for patients with NTSCI admitted to one of the three specialized SCI departments in Norway during the study period. The NTSCI and TSCI groups were compared using the Mann-Whitney $U$ test and chi-square test.

\section{Study variables}

The current study from NorSCIR used the International SCI Core Data Set (version 1.1), as recommended by the International Spinal Cord Society (ISCoS). This dataset includes the birth date, injury date, acute admission date, final inpatient discharge date, total days hospitalized, gender, injury etiology, vertebral injury information, associated injuries, spinal surgery information, ventilatory assistance status at discharge from hospital, place of discharge, and neurological data for each patient [6]. The International SCI Core Data Set (version 1.1) does not distinguish between different non-traumatic causes. The International Standards for Neurological Classification of SCI (ISNCSCI) includes the clinical findings standardized by the American Spinal Injury Association (ASIA) Impairment Scale (AIS) [7-9].

\section{Data collection and analysis}

NorSCIR uses the International SCI Data Sets, which were developed by ISCoS. The registry is electronic and runs on the Microsoft-based Medical Registry System (MRS) developed by the Central Norway Regional Health Authority's IT department (Hemit). Data are sent through the Norwegian Health Network.
Data collection and registration were conducted during each patient's primary stay at the specialized SCI department during the study period. The neurological level of the injury and degree of impairment after the injury were assessed by a medical doctor specialized in spinal cord injury, most often together with a physiotherapist, using the International Standards for Neurological Classification of SCI (ISNCSCI). The examination was usually performed during the first week after admission and during the last week before discharge from the specialized SCI department.

The analyses followed the recommendations of the International Spinal Cord Injury Core Data Set [10]. Continuous variables are expressed as both means with standard deviations and medians with ranges. Categorical variables are presented as the number of cases and percentages. The categorization of age groups has been done according to the newest recommendations [11]. Participants' demographic information and injury characteristics were analyzed descriptively. Population data from Statistics Norway [3] were obtained to calculate the annual incidence rates of spinal cord injury patients admitted for primary rehabilitation per million person-years; these data were stratified by age and gender. The WHO standard population was used to calculate the age-standardized incidence [12].

IBM SPSS Statistics version 23 and Microsoft Excel 2010 were used to perform all of the statistical analyses. The TSCI and NTSCI groups were compared using the chisquare test and the Mann-Whitney $U$ test.

\section{Ethical and legal aspects}

The NorSCIR registry is approved by the Norwegian Data Protection Authority (09/01084-2/CGN). Registration in the registry is voluntary, and written consent is obtained before registration occurs.

Ethical approval for this study was obtained from regional committees for medical and health research ethics (registration code 2017/1092).

\section{Results}

In the period from 2012 to 2016,574 individuals with a recent SCI or cauda equina injury were registered. Of those individuals, 225 suffered an NTSCI.

\section{Incidence}

The incidence of NTSCI varied between 7.7 and 10.4 per million person-years in the period from 2012 to 2016 . Available data from NorSCIR on incidences of NTSCI are described in Table 1. 
Table 1 NTSCI incidences based on data from NorSCIR, 2012-2016* $(n=225)$, incidence rates per million person-years

\begin{tabular}{llllll}
\hline & 2012 & 2013 & 2014 & 2015 & 2016 \\
\hline Number of cases per year & 52 & 42 & 43 & 48 & 40 \\
Incidence per year & 10.4 & 8.3 & 8.4 & 9.3 & 7.7 \\
Age-standardized incidence & 7.6 & 6.0 & 6.4 & 7.1 & 5.8 \\
Incidence by gender & & & & & \\
Male & 11.6 & 9.9 & 9.0 & 10.8 & 10.3 \\
Female & 9.3 & 6.8 & 7.9 & 7.8 & 5.0 \\
Incidence by age & & & & & \\
0-14 & 0.0 & 1.1 & 1.1 & 1.1 & 1.1 \\
15-29 & 5.1 & 1.0 & 4.0 & 2.9 & 2.9 \\
30-44 & 6.7 & 8.5 & 4.7 & 5.7 & 3.8 \\
$45-59$ & 12.3 & 12.1 & 12.9 & 18.5 & 14.5 \\
$60-74$ & 37.0 & 22.1 & 24.2 & 19.7 & 16.6 \\
$75+$ & 5.7 & 8.5 & 5.6 & 11.1 & 11.0 \\
\hline
\end{tabular}

*Table 1 presents results based on data from NorSCIR. All cases may not be included due to NorSCIR inclusion criteria. For example, patients with progressive NTSCI are rarely admitted for rehabilitation at a SCI unit

NOTE: Incidences of TSCI are described in a separate article.

\section{Epidemiological characteristics of NTSCI}

Demographic and clinical characteristics of the NTSCI patients are presented in Table 2. Out of the 225 individuals suffering an NTSCI, 59\% were male, and the mean age was 55 years $(\mathrm{SD}=17)$. The youngest patient was 7 years old, and the oldest was 83 years old. The average total length of stay, from admission to the acute hospital to discharge from the specialized SCI department, was 97 days, with a median of 98 days (min 4 days, max 277). The length of stay in our study was defined as the total number of acute days and rehabilitation days, while days "out of hospital" were subtracted. The place of discharge from primary rehabilitation was most often home $(73 \%)$, while $7 \%$ were discharged to a nursing home. The mean age of patients discharged to a nursing home was 63 years (median 72, minimum 22, and maximum 78). Three individuals with SCI required ventilatory assistance to sustain respiration on the date of final inpatient discharge. The distribution of tetra- and paraplegia based on the International Standards for Neurological Classification of SCI [9] at admission was 22 and 69\%, respectively, with $9 \%$ of the patients not classified.

The majority $(59 \%)$ of the NTSCI individuals were graded as AIS D at admission.

Information on neurological lesion levels and AIS classifications both at admission and discharge was available for 153 of the 225 cases $(68 \%)$. Out of the 25 patients initially classified as AIS grade A at admission, $60 \%$ remained AIS grade A at discharge. We observed considerable changes during primary rehabilitation for those with incomplete lesions. These details are presented in Table 3.

\section{Comparisons between traumatic spinal cord injury and non-traumatic spinal cord injury}

There were more patients with TSCI than NTSCI (61\% vs. $39 \%$ ) in specialized SCI departments during the study period. Demographic characteristics and outcomes in the two groups are shown in Table 4. The NTSCI patients were older than the TSCI patients. Patient age for the study sample was not normally distributed. A Mann-Whitney $U$ test comparing the age distribution in the two groups gave a $p$ value of $<0.0001$. The proportion of men was larger in the TSCI group than in the NTSCI group (chi-square test $p<$ 0.0001 ). The total length of stay in the hospital was longer for the TSCI patients than the NTSCI patients (median 108 days for TSCI and 98 days for the NTSCI patients, $p<$ 0.0001 , Mann-Whitney $U$ test). The table shows that the neurological impairments in most cases were more severe after a TSCI than an NTSCI. The risk of a complete lesion is lower for patients suffering from NTSCI than patients with TSCI $(p<0.0001)$. The majority of the NTSCI cases were graded as AIS D at admission. Comparisons in neurological improvements after rehabilitation between the two groups are challenging due to differences in levels and severities of injury or comorbidities.

\section{Discussion}

The crude incidence of NTSCI in our study was between 7.7 and 10.4 per million person-years, somewhat higher than the age-standardized incidence. This is related to the proportion of elderly people in the Norwegian population. In a review of NTSCI global epidemiology [13], the median incidence rate was calculated to be 6 per million population per year based on data available from eight countries in Western Europe. In the same review, much higher incidence rates were found for other developed regions; Australasia and Canada had 26 and 68 incidents per million personyears, respectively.

Our results show that individuals with NTSCI are older and less severely injured, and their lengths of stay in hospitals are shorter than the TSCI individuals. A shorter length of stay has been shown to be typical for non-traumatic SCI and may be related to less severe injuries [14]. The proportion of patients discharged to home is almost similar for both NTSCI and TSCI. These results are in line with those of other studies $[15,16]$.

The mean age for NTSCI was 55 years, which was higher than the mean age for TSCI (47 years). The finding is in line with a previously reported study [14]. However, it 
Table 2 General data on epidemiology of NTSCI

\begin{tabular}{|c|c|c|c|c|c|c|c|c|c|c|c|c|}
\hline \multirow{4}{*}{$\begin{array}{l}\text { Number of cases of NTSCI } \\
\text { Mean age (SD) }\end{array}$} & \multirow{2}{*}{\multicolumn{2}{|c|}{$\frac{2012}{52}$}} & \multirow{2}{*}{\multicolumn{2}{|c|}{$\frac{2013}{42}$}} & \multirow{2}{*}{\multicolumn{2}{|c|}{$\frac{2014}{43}$}} & \multicolumn{2}{|c|}{2015} & \multicolumn{2}{|c|}{2016} & \multicolumn{2}{|c|}{ Total } \\
\hline & & & & & & & 48 & & 40 & & 225 & \\
\hline & \multicolumn{2}{|c|}{57 (17) } & \multicolumn{2}{|c|}{$55(16)$} & \multicolumn{2}{|c|}{54 (16) } & \multicolumn{2}{|c|}{$54(16)$} & \multicolumn{2}{|c|}{$55(18)$} & \multicolumn{2}{|c|}{$55(17)$} \\
\hline & $N$ & $\%$ & $N$ & $\%$ & $N$ & $\%$ & $N$ & $\%$ & $N$ & $\%$ & $N$ & $\%$ \\
\hline \multicolumn{13}{|l|}{ Age } \\
\hline $0-14$ & 0 & $(0.0)$ & 1 & $(2.4)$ & 1 & $(2.3)$ & 1 & (2.1) & 1 & $(2.5)$ & 4 & (1.8) \\
\hline $15-29$ & 5 & $(9.6)$ & 1 & $(2.4)$ & 4 & $(9.3)$ & 3 & (6.3) & 3 & $(7.5)$ & 16 & (7.1) \\
\hline $30-44$ & 7 & (13.5) & 9 & (21.4) & 5 & (11.6) & 6 & (12.5) & 4 & $(10.0)$ & 31 & (13.8) \\
\hline $45-59$ & 12 & (23.1) & 12 & (28.6) & 13 & $(30.2)$ & 19 & (39.6) & 15 & (37.5) & 71 & (31.6) \\
\hline $60-74$ & 26 & $(50.0)$ & 16 & $(38.1)$ & 18 & (41.9) & 15 & (31.3) & 13 & $(32.5)$ & 88 & $(39.1)$ \\
\hline $75+$ & 2 & $(3.8)$ & 3 & (7.1) & 2 & (4.7) & 4 & (8.3) & 4 & $(10.0)$ & 15 & (6.7) \\
\hline \multicolumn{13}{|l|}{ Gender } \\
\hline Male & 29 & $(55.8)$ & 25 & $(59.5)$ & 23 & $(53.5)$ & 28 & $(58.3)$ & 27 & $(67.5)$ & 132 & (58.7) \\
\hline Female & 23 & $(44.2)$ & 17 & $(40.5)$ & 20 & $(46.5)$ & 20 & (41.7) & 13 & $(32.5)$ & 93 & (41.3) \\
\hline \multicolumn{13}{|c|}{ Level of injury and AIS at admission } \\
\hline $\mathrm{C} 1-\mathrm{C} 4$ AIS A-C & 0 & $(0.0)$ & 0 & $(0.0)$ & 1 & $(2.3)$ & 0 & $(0.0)$ & 2 & $(5.0)$ & 3 & (1.3) \\
\hline C5-C8 AIS A-C & 0 & $(0.0)$ & 2 & $(4.8)$ & 1 & $(2.3)$ & 0 & $(0.0)$ & 0 & $(0.0)$ & 3 & (1.3) \\
\hline Paraplegia AIS A-C & 18 & $(34.6)$ & 14 & $(33.3)$ & 11 & $(25.6)$ & 11 & $(22.9)$ & 12 & $(30.0)$ & 66 & $(29.3)$ \\
\hline All AIS D & 26 & $(50.0)$ & 19 & $(45.2)$ & 30 & $(69.8)$ & 34 & $(70.8)$ & 23 & $(57.5)$ & 132 & $(58.7)$ \\
\hline All AIS E & 0 & $(0.0)$ & 0 & $(0.0)$ & 0 & $(0.0)$ & 0 & $(0.0)$ & 1 & $(2.5)$ & 1 & $(0.4)$ \\
\hline Unknown or not applicable & 8 & $(15.4)$ & 7 & $(16.7)$ & 0 & $(0.0)$ & 3 & $(6.3)$ & 2 & $(5.0)$ & 20 & $(8.9)$ \\
\hline \multicolumn{13}{|l|}{ Neurological level of injury } \\
\hline Tetraplegia & 9 & $(17.3)$ & 8 & $(19.0)$ & 12 & $(27.9)$ & 12 & $(25.0)$ & 8 & $(20.0)$ & 49 & $(21.8)$ \\
\hline Paraplegia & 35 & $(67.3)$ & 27 & $(64.3)$ & 30 & $(69.8)$ & 34 & $(70.8)$ & 30 & $(75.0)$ & 156 & $(69.3)$ \\
\hline Unknown or not applicable & 8 & $(15.4)$ & 7 & $(16.7)$ & 1 & $(2.3)$ & 2 & $(4.2)$ & 2 & $(5.0)$ & 20 & $(8.9)$ \\
\hline \multicolumn{13}{|l|}{ Discharge location } \\
\hline Home & 40 & $(76.9)$ & 32 & $(76.2)$ & 32 & $(74.4)$ & 30 & $(62.5)$ & 31 & $(77.5)$ & 165 & (73.3) \\
\hline Other & 12 & (23.1) & 10 & $(23.8)$ & 11 & (25.6) & 18 & $(37.5)$ & 9 & $(22.5)$ & 60 & (26.7) \\
\hline
\end{tabular}

AIS American Spinal Injury Association Impairment Scale, AIS A motor-sensory

complete, AIS B motor complete-sensory incomplete, AIS $C-D$ motor-sensory incomplete, AIS

$E$ normal examination, NTSCI non-traumatic spinal cord injury should be pointed out that the difference between TSCI and NTSCI was only 8 years. Our study demonstrates that both persons with TSCI and NTSCI are middle-aged. This contradicts previous assertion that persons with TSCI belong to a young age group. Probably will composition of the TSCI and NTSCI group depend on geography, as well as cultural and traditional characteristics. During the 5-year study period, only 15 persons (7\%) greater than 75 years of age with non-traumatic SCI were registered. The explanation for this may be that elderly patients with non-traumatic SCI are transferred to a specialized SCI department less often, for example because of comorbidities. The male-to-female ratio was still favored by men, but less so in the NTSCI group than in the TSCI group.

We observed that, in contrast to the TSCI group, few cervical lesions with ASIA impairment scale grades of A, B, or $\mathrm{C}$ were found in the NTSCI group. This finding may be explained by the underlying etiology of the NTSCI dominating levels of the injury, for example, tumors at the thoracic level and degenerative problems in the lumbosacral region [17-19]. Only three out of 225 patients required ventilatory assistance to sustain respiration on the date of final inpatient discharge. Few observed patients with complete NTSCI may explain why the length of stay in this group was shorter. Shorter rehabilitation time for NTSCI has been demonstrated previously $[14,18]$. The completeness and level of SCI should be taken into account in this discussion.

Previous study demonstrated that persons with NTSCI have higher odds for institutionalization [14]. Our study cannot confirm these findings. The majority of persons with NTSCI were discharged home. This finding may be characteristic for Scandinavian countries and be dependent on cultural characteristics as well as results of rehabilitation. This finding should encourage to evaluate patients with NTSCI individually. 
Table 3 Changes in AIS grades during primary rehabilitation for NTSCI from admission to discharge from the SCI department

\begin{tabular}{|c|c|c|c|c|c|c|c|c|c|c|c|c|c|}
\hline & \multicolumn{13}{|c|}{ AIS at discharge } \\
\hline & & A & Complete & B & Incomplete & $\mathrm{C}$ & Incomplete & $\mathrm{D}$ & Incomplete & $\mathrm{E}$ & Normal & $\mathrm{U}$ & $\begin{array}{l}\text { Unknown or not } \\
\text { applicable }\end{array}$ \\
\hline AIS at admission & Total & $N$ & $\%$ & $N$ & $\%$ & $N$ & $\%$ & $N$ & $\%$ & $N$ & $\%$ & $N$ & $\%$ \\
\hline A complete injury & 25 & 15 & 60 & 2 & 8 & 1 & 4 & 1 & 4 & 0 & 0 & 6 & 24 \\
\hline B Incomplete injury & 18 & 0 & 0 & 4 & 22 & 6 & 33 & 4 & 22 & 0 & 0 & 4 & 22 \\
\hline $\mathrm{C}$ Incomplete injury & 29 & 0 & 0 & 2 & 7 & 14 & 48 & 9 & 31 & 0 & 0 & 4 & 14 \\
\hline D Incomplete injury & 132 & 0 & 0 & 0 & 0 & 0 & 0 & 92 & 70 & 3 & 2 & 37 & 28 \\
\hline E Normal & 1 & 0 & 0 & 0 & 0 & 0 & 0 & 0 & 0 & 0 & 0 & 1 & 100 \\
\hline $\begin{array}{l}\text { U Unknown or not } \\
\text { applicable }\end{array}$ & 17 & 2 & 12 & 0 & 0 & 1 & 6 & 12 & 71 & 0 & 0 & 5 & 29 \\
\hline Total & 225 & 17 & 8 & 8 & 4 & 22 & 10 & 118 & 52 & 3 & 1 & 57 & 25 \\
\hline
\end{tabular}

Table 4 Demographics and outcomes for non-traumatic and traumatic spinal cord injuries

\begin{tabular}{|c|c|c|c|}
\hline & $\begin{array}{l}\text { Non-traumatic SCI } \\
(n=225)\end{array}$ & $\begin{array}{l}\text { Traumatic SCI } \\
(n=349)\end{array}$ & $p$ Value \\
\hline Mean age (SD) & $55(17)$ & 47 (19) & $<0.0001^{*}$ \\
\hline Median age & 58 & 49 & \\
\hline \multicolumn{4}{|l|}{ Gender (\%) } \\
\hline Male & $132(59)$ & $265(76)$ & \\
\hline Female & $93(41)$ & $84(24)$ & $<0.0001^{*}$ \\
\hline \multicolumn{4}{|c|}{ Total length of stay in days } \\
\hline Mean (SD) & $97(53)$ & $120(62)$ & \\
\hline Median & 98 & 108 & $<0.0001^{*}$ \\
\hline \multicolumn{4}{|c|}{ Level of injury and AIS at admission } \\
\hline $\mathrm{C} 1-\mathrm{C} 4$ AIS A-C & $3(1.3)$ & $61(17.5)$ & \\
\hline $\mathrm{C} 5-\mathrm{C} 8$ AIS A-C & $3(1.3)$ & $19(5.4)$ & \\
\hline $\begin{array}{l}\text { Paraplegia AIS } \\
\text { A-C }\end{array}$ & $66(29.3)$ & $86(24.6)$ & \\
\hline All AIS D & $132(58.7)$ & $150(43.0)$ & \\
\hline All AIS E & $1(0.4)$ & $2(0.6)$ & \\
\hline $\begin{array}{l}\text { Unknown or not } \\
\text { applicable }\end{array}$ & $20(8.9)$ & $31(8.9)$ & \\
\hline \multicolumn{4}{|c|}{ Neurological level of injury } \\
\hline Tetraplegia & $49(21.8)$ & $169(48)$ & \\
\hline Paraplegia & $156(69.3)$ & $146(42)$ & \\
\hline $\begin{array}{l}\text { Unknown or not } \\
\text { applicable }\end{array}$ & $20(8.9)$ & $34(9.7)$ & \\
\hline $\begin{array}{l}\text { Discharged to } \\
\text { home }\end{array}$ & $165(73.3)$ & $238(68.2)$ & \\
\hline $\begin{array}{l}\text { Ventilatory } \\
\text { assistance at } \\
\text { discharge }\end{array}$ & $3(1.3)$ & $15(4.3)$ & \\
\hline
\end{tabular}

*Mann-Whitney $U$ test (age distribution)

${ }^{* *}$ Chi-square test

\section{Data archiving}

The data used in this study are from the Norwegian Spinal Cord Injury Registry. There are restrictions on the use of data from a national medical quality registry. These data were used under licence for the current study, and are not publicly available. Some of the used data are available from the corresponding author on reasonable request.

\section{Limitations}

Rehabilitation of individuals with NTSCI is conducted in different settings, and it is likely that not all individuals with this condition were admitted to one of the three SCI units, which is an inclusion criterion for NorSCIR. We are aware that some persons with NTSCI were managed in non-SCI specialized departments. This makes the analyzed sample less complete. For example, persons with spina bifida or multiple sclerosis are not reported in the registry. This results in an underestimation of the incidence of NTSCI. However, we believe that our study describes and involves the majority of patients with nonprogressive NTSCI. Etiological causes of NTSCI were, unfortunately, not collected during the study period. The Norwegian SCI registry has implemented International SCI Core Data Set Version 2.0 from 2018. This allows us to present the distribution of different non-traumatic causes in the future.

\section{Main conclusion and an indication of the direction for future research}

The Norwegian SCI registry provides a unique opportunity to monitor and improve SCI health services. For the first time, we are able to give the national epidemiological status of NTSCI in Norway. Our results show a lower incidence of 
NTSCI than TSCI in NorSCIR but a higher incidence than previously estimated for Western Europe. Individuals with NTSCI are significantly older and less severely injured, and their lengths of stay at the hospital are shorter than the individuals with TSCI.

Rehabilitation of individuals with NTSCI is conducted in different settings and not always in specialized SCI departments; therefore, the true incidence is probably somewhat higher than our estimate. Further studies are required to improve the capture of NTSCI for future incidence studies.

NTSCI patients may experience better outcomes due to the experienced staff in specialized SCI departments. Further studies are required to determine the best setting for the rehabilitation of NTSCI patients.

Acknowledgements We acknowledge the three SCI specialized centers, located at Haukeland University Hospital, St. Olav's University Hospital, and Sunnaas Rehabilitation Hospital for registration in the Norwegian SCI registry. We would like to thank all members of the Norwegian SCI registry steering committee for support and data collection, and the National Spinal Cord Injuries Association for good cooperation and enthusiasm.

Authors' contributions AH, ALP, and TR analyzed and interpreted the data, prepared, and revised manuscript content. SMN in collaboration with $\mathrm{KKH}$ provided statistical guidance/support and critically revised the manuscript content. AH, ALP, TR, and EES also critically revised manuscript content and supported data collection. All authors have given their final approval of the version to be submitted.

Funding This study was financed by St. Olav's University Hospital, Trondheim, Norway. SMN was funded by the Norwegian research council (Grant number 256579).

\section{Compliance with ethical standards}

Conflict of interest The authors declare that they have no conflict of interest.

\section{References}

1. Biering-Sorensen F, Charlifue S, DeVivo M, Noonan V, Post M, Stripling T, et al. International spinal cord injury data sets. Spinal Cord. 2006;44:530-4.

2. ISCoS The International Spinal Cord Society. Prevention Committee. Strategic Plan. Available from: http://www.iscos.org.uk// strategic-plan; 2018 [cited 2018 July 6].

3. Statistics Norway. Folkemengde per 1. januar, fødte, døde, flyttinger og folketilvekst (SA 48) Oslo: Statistics Norway; 2018 [cited 2018 February 23]. Available from: https://www.ssb.no/ 300132/folkemengde-per-1.januar-fodte-dode-flyttinger-ogfolketilvekst-sa-48.
4. Halvorsen A, Pettersen AL, Nilsen SM, Halle KK, Schaanning EE, Rekand T. Epidemiology of traumatic spinal cord injury in Norway in 2012-2016: a registry-based cross-sectional study; 2018 [Accepted for publication in Spinal Cord 2018 November 8].

5. Halvorsen A, Pettersen AL. Norwegian SCI registry Trondheim: St Olavs Hospital. Available from: https://stolav.no/fag-ogforskning/medisinske-kvalitetsregistre/norsk-ryggmargsska deregister-norscir\#rapporter; 2018 [cited 2018 July 6]

6. DeVivo M, Biering-Sorensen F, Charlifue S, Noonan V, Post M, Stripling $\mathrm{T}$, et al. International spinal cord injury core data set. Spinal Cord. 2006;44:535-40.

7. Marino RJ, Barros T, Biering-Sorensen F, Burns SP, Donovan $\mathrm{WH}$, Graves DE, et al. International standards for neurological classification of spinal cord injury. J Spinal Cord Med. 2003;26: S50-s6.

8. Waring WP 3rd, Biering-Sorensen F, Burns S, Donovan W, Graves D, Jha A, et al. 2009 review and revisions of the international standards for the neurological classification of spinal cord injury. J Spinal Cord Med. 2010;33:346-52.

9. Kirshblum SC, Burns SP, Biering-Sorensen F, Donovan W, Graves DE, Jha A, et al. International standards for neurological classification of spinal cord injury (revised 2011). J Spinal Cord Med. 2011;34:535-46.

10. DeVivo MJ, Biering-Sorensen F, New P, Chen Y. Standardization of data analysis and reporting of results from the International Spinal Cord Injury Core Data Set. Spinal Cord. 2011; 49:596-9.

11. Biering-Sorensen F, DeVivo MJ, Charlifue S, Chen Y, New PW, Noonan V, et al. International Spinal Cord Injury Core Data Set (version 2.0)-including standardization of reporting. Spinal Cord. 2017;55:759-64.

12. Ahmad OB, Boschi-Pinto C, Lopez AD, Murray CJL, Lozano R, Inoue M. Age standardization of rates: a new who standard. GPE Discussion Paper Series: No. 31: World Health Organization. Available from: https://www.who.int/healthinfo/paper31.pdf; 2001 [cited 2018 May 11]

13. New PW, Cripps RA, Bonne Lee B. Global maps of non-traumatic spinal cord injury epidemiology: towards a living data repository. Spinal Cord. 2014;52:97-109.

14. Clark JM, Marshall R. Nature of the non-traumatic spinal cord injury literature: a systematic review. Top Spinal Cord Inj Rehabil. 2017;23:353-67.

15. Post MWM, Nachtegaal J, van Langeveld SA, van de Graaf M, Faber WX, Roels EH, et al. Progress of the Dutch Spinal Cord Injury Database: completeness of database and profile of patients admitted for inpatient rehabilitation in 2015. Top Spinal Cord Inj Rehabil. 2018;24:141-50.

16. New PW, Simmonds F, Stevermuer T. A population-based study comparing traumatic spinal cord injury and non-traumatic spinal cord injury using a national rehabilitation database. Spinal Cord. 2011;49:397-403.

17. Ones K, Yilmaz E, Beydogan A, Gultekin O, Caglar N. Comparison of functional results in non-traumatic and traumatic spinal cord injury. Disabil Rehabil. 2007;29:1185-91.

18. McKinley WO, Seel RT, Hardman JT. Non-traumatic spinal cord injury: incidence, epidemiology, and functional outcome. Arch Phys Med Rehabil. 1999;80:619-23.

19. McKinley WO, Conti-Wyneken AR, Vokac CW, Cifu DX. Rehabilitative functional outcome of patients with neoplastic spinal cord compressions. Arch Phys Med Rehabil. $1996 ; 77: 892-5$. 


\section{Affiliations}

\section{A. Halvorsen ${ }^{1,2} \cdot$ A. L. Pettersen ${ }^{1}$ - S. M. Nilsen ${ }^{1,3} \cdot$ K. Krizak Halle ${ }^{1}$ E. Elmenhorst Schaanning ${ }^{4} \cdot$ T. Rekand $\mathbb{B}^{5,6}$}

1 Department of Medical Quality Registries, St. Olavs Hospital, Trondheim University Hospital, Trondheim, Norway

2 Clinic of Physical Medicine and Rehabilitation, Department of Spinal Cord Injuries, St. Olavs Hospital, Trondheim University Hospital, Trondheim, Norway

3 Center for Health Care Improvement, St. Olavs Hospital, Trondheim University Hospital, Trondheim, Norway
4 Department of Spinal Cord Injury, Follow Up (Inpatient), Sunnaas Rehabilitation Hospital, Nesodden, Norway

5 Department of Neurology, Haukeland University Hospital, Bergen, Norway

6 Sahlgrenska Academy, Institute for Physiology and Neuroscience, University of Gothenburg, Gothenburg, Sweden 